\title{
The Rooms Air Conditioning by Cooling the Conventional Water Tank Using Hot Summer Air and Solar Energy
}

\author{
Hasan Shakir Majdi ${ }^{*}$, Faez Abid Muslim Abd Ali², Laith Jaafer Habeeb ${ }^{3}$ \\ ${ }^{1}$ Chemical and Petroleum Industries Engineering Department, Al-Mustaqbal University College, Babylon, Hillah 51001, Iraq \\ ${ }^{2}$ Mechanical Engineering Department, Faculty of Engineering, University of Kufa, Al Najaf 54001, Iraq \\ ${ }^{3}$ Training and Workshops Center, University of Technology, Bagdad 10001, Iraq
}

Corresponding Author Email: Hasanshker@mustaqbal-college.edu.iq

https://doi.org/10.18280/ijht.380224

Received: 4 February 2020

Accepted: 17 May 2020

\section{Keywords:}

evaporative cooling, heat and mass transfer, house water tanks, test room

\begin{abstract}
In the present work, an experimental study has been carried out to investigate a method to reduce the water tank temperature and used it in room air condition. The tests were conducted in the hot season (July and August) in Iraq. The results proved that the device succeeded in reducing the water tank temperature to $23^{\circ} \mathrm{C}$, which is a low temperature in the summer and kept at this value by continuous work of the device. It was almost constant at the hot afternoon compared to the temperature of the uncooled tank, which reached its temperature at $2: 00 \mathrm{pm}$ to about $43^{\circ} \mathrm{C}$ and the difference was $46.5 \%$. The dry air temperature of the test room is very close to the temperature of the house room air (30$33)^{\circ} \mathrm{C}$, compared to the ambient temperature (45-50) ${ }^{\circ} \mathrm{C}$. Decrease in the relative humidity to (51-45) \% for the test room compared with house room (94-90) \%. The power consumption of the system is lower than traditional air evaporative cooler in a rate of $67 \%$.
\end{abstract}

\section{INTRODUCTION}

As the summer of many countries like Iraq comes, the temperatures in the afternoon hours reach more than $50^{\circ} \mathrm{C}$, especially in the months of July and August [1]. The temperature rises for each object that is exposed to the external environment due to its impact on the high ambient temperature and its absorption of sun radiation, depending on the absorption of the bodies [2]. Water tanks placed on high towers (suitable for pressure drainage) or on the roofs of buildings, which makes them more vulnerable to the external atmosphere and direct sun radiation. That leads to increase the water temperature inside it to the point of challenging to use, and the fact that the water is almost high thermal capacity, so keep the heat for a long time as the water stays hot even at night [3]. The temperature of the tanks varies depending on the size, the nature of the manufacturing material, the color of the outer surface and the method of thermal insulation, or placed under the shade or exposed to direct sun radiation [4]. There have been several attempts to reduce the impact of reservoirs in the external ambient, but no scientific research conducted on this subject.

The direct evaporative cooling method is one of the major methods of air cooling and has many different techniques; this method succeeded in hot and dry climate [5]. It is a heat and mass transfer process, which a large amount of heat transferred from air to water, and consequently the air temperature decreases [6]. Mass transfer from the water as a vapor, the heat required for evaporation absorbed from the air and water, and the air is cooled as well as the water; the water temperature decrease too as in cooling towers [7]. Keister [8] studied the cooling water management basic principles and technology. Evaporation of $0.45 \mathrm{~kg}$ of water requires about $0.3 \mathrm{~kW}$, makes the evaporative cooling tower the most effective means for this heat transfer, typically $75 \%$ to $80 \%$ of the heat is removed from the cooling water by evaporation. Misra and Ghosh [9] studied the evaporative cooling technologies for greenhouses. Evaporative cooling has completely revolutionized the system of cooling in building, facilities and greenhouses since the nineteenth century and still it is being used around the world. Vairagade et al. [10] make a review paper on evaporative cooling methods and shows that the indirect evaporative cooling decreases the temperature of air via some type of heat exchanger system, in which a secondary stream air is cooled by water and which in turn cools the primary stream air. The cooled air never comes in direct contact with water or environment. Indirect evaporative cooling system both the dry bulb and wet bulb temperature are reduced. Indirect evaporative cooler does not add humidity to the air, but cost more than direct coolers and operate at a lower efficiency, the efficiency of indirect cooling is in the range of $60 \%$ to $70 \%$. From the above studies, results were encouraging to conduct the research, as the amount of heat removed from the water is high. In addition, the method was adopted in this research because of its economic benefits, as well as the success of the indirect evaporative cooling method. Which helps to provide air cooling without adding moisture and will be proven in this study that done in a hot weather.

In this work, a method was used to reduce the temperature of water tank using a device that propels the air into the tank to increase evaporation of water and thus take the latent heat to evaporate from the water tank. To increase water evaporation, the device recycles the water inside the tank by a small water pump and descends the water in the shape of a small waterfall to increase the contact area of water with air. Cooled water was used in the air conditioning of the test room. This technology solves the problem of hot water in water tanks, which are difficult for daily use in hot climates. So, the use of 
cooled water to cool the air, thereby providing cold water and cold air by a little electrical energy. The test was conducted in Iraqi ambient because of high temperatures and scarcity of electrical energy, where more than half the energy generated spend by the air conditioner and refrigeration systems.

\section{DESCRIPTION OF THE EXPERIMENTAL SETUP}

The device consists of water tank capacity (500 liters), and a centrifugal fan has a diameter of $(25 \mathrm{~cm})$ with an electrical motor $(12 \mathrm{~V}, 2.14 \mathrm{~A}) \mathrm{DC}$. The fan installed on the tank cover where the fan nozzle $(10 \mathrm{~cm})$ is inserted inside the tank to propel the air on the surface of the water. The air exhales with water vapor through holes in the shell cover as shown in Figure 1. A rectangular rod of aluminum $(80 \mathrm{~cm})$ is attached to the bottom of the tank, and an electric water pump installed at the end of the rod, which operated on $(12 \mathrm{~V}, 375 \mathrm{~mA}) \mathrm{DC}$. The water is pushed from the bottom of the tank to the top cover by a rubber tube to drain the water from the holes ( 20 holes) with a diameter $(2 \mathrm{~mm})$.

The water tank (500 liters) made of polyethylene; centrifugal fan installed to the cover, pulls the outside air through the filter of dimensions $(30 \times 30) \mathrm{cm}$. Air gap dimensions are $(6 \times 20) \mathrm{cm}$ enters the air to the tank where the air hits the water surface and comes out of the tank cover through (100 holes) diameter $(3 \mathrm{~mm})$. An aluminum arm installed with the propeller body and a length of $(80 \mathrm{~cm})$. Four thermocouples were set up each $(15 \mathrm{~cm})$ to measure the temperature changes in the layers of the tank water. At the end of the lower arm, a water pump installed, which push the water upward by a rubber tube containing (20) circular holes with the diameter $(2 \mathrm{~mm})$, to increase water contact with the air and thus increase the evaporation rate. The water holes distributed as an inner circle around the air intake hole of the fan and air exit slots with an outer circle to intersect the outside air with the water, Figure 2. Then the cold water at the top surface is moving down because of density and gravity, and the hot water is moving up. A wooden box was manufactured as an insulator from the external environment with dimensions $(90 \times 120 \times 90)$ $\mathrm{cm}$, with a roof from wood with dimensions of $(300 \times 300) \mathrm{cm}$ to give a shadow to the tank, Figure 3. The test was done first using the device with the reservoir and without the usual insulation, and then a wooden box put to be a thermal insulation and protection from external conditions and then wooden roof was placed to provide shade for the system.

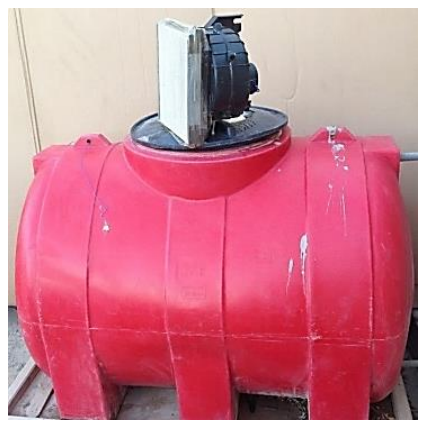

Figure 1. Installation of the device on the water tank

A room was constructed of wood (MDF) with a thickness of $(1.5 \mathrm{~cm})$ and with a dimension of $(140 \times 140 \times 200) \mathrm{cm}$ as a laboratory space and it was isolated by glass wool thickness $(2 \mathrm{~cm})$. Inside the room a forced heat exchanger (fan coil unit) 2TR capacity, cold water supplied from the cooled tank to the heat exchanger tubes to cool the flow air circulating by the centrifugal fan. Supplying water with thermally insulated plastic pipes and a water pump.

The system shall be powered by a solar energy system consisting of a solar panel measuring $(60 \times 150) \mathrm{cm}$, and with the following standard specifications (Table 1):

Table 1. Solar panel specification

\begin{tabular}{cc}
\hline Peak power (+15-5\%) (Pmax) & $150 \mathrm{~W}$ \\
\hline Open-circuit voltage (Voc) & $22.5 \mathrm{~V}$ \\
Short-circuit current (Isc) & $9.10 \mathrm{~A}$ \\
Peak voltage (Vmpp) & $17.8 \mathrm{~V}$ \\
Peak current (Impp) & $8.42 \mathrm{~A}$ \\
Maximum system voltage & $600 \mathrm{~V}$ \\
Over-current protection & $30 \mathrm{~A}$ \\
Series fuse rating & $15 \mathrm{~A}$ \\
\hline
\end{tabular}

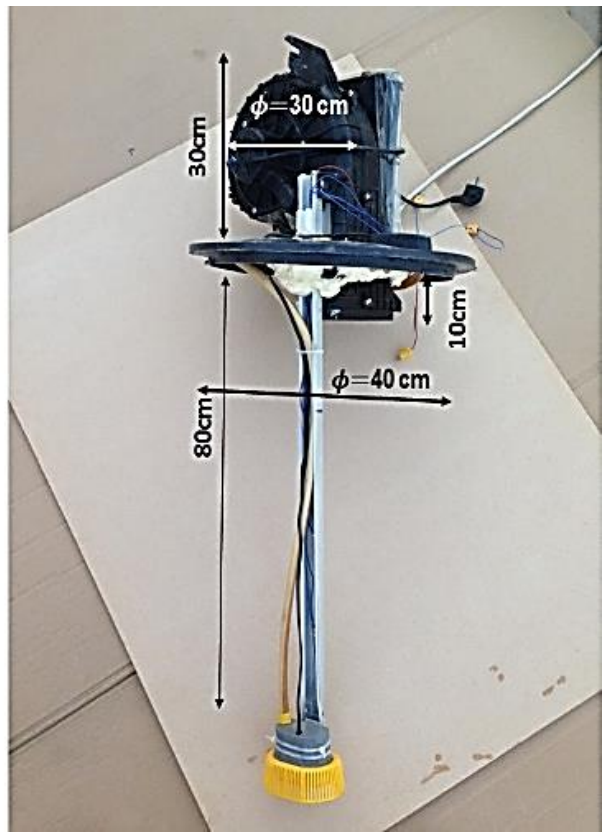

Figure 2. Parts of the device 


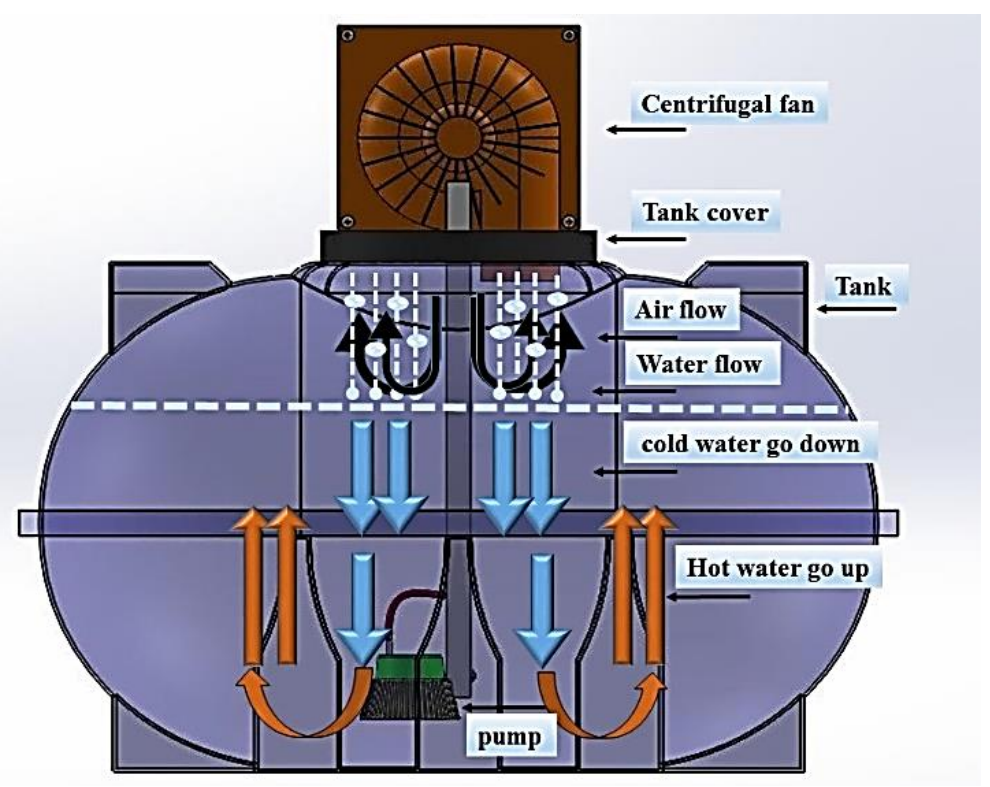

Figure 3. Movement of water and air inside the tank

Connects with the solar panel a voltage controller to regulate the solar panel voltage (DC) and connected to the battery for charging. For the operation of the device fan and the water pump running on alternating current and 220 volts, a power inverter (UPS) (3.2 A) was used, which receive the power from battery $(60 \mathrm{~A}, 12 \mathrm{~V})$. The result of the whole system is to be according to Figure 4.

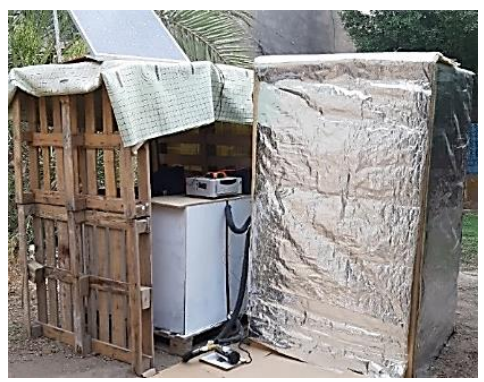

Figure 4. Final form of the system
Multi-channel temperature meter is used, type (AT4532) LCD display and 32 channels, with thermocouples type K were used. Four thermocouples in the water tank to measure the water temperature Figure 2, two for ambient, two for air outlet from water tank, two for test room and two for home room to measure wet and dry temperatures, Figure 5.

The schematic diagram of the system shown in Figure 6.

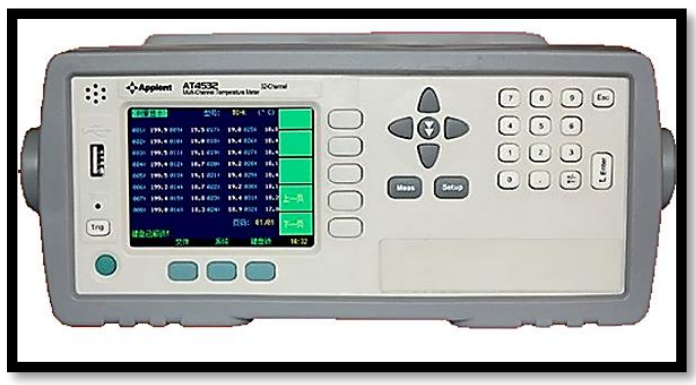

Figure 5. AT4532 multi-channel temperature meter

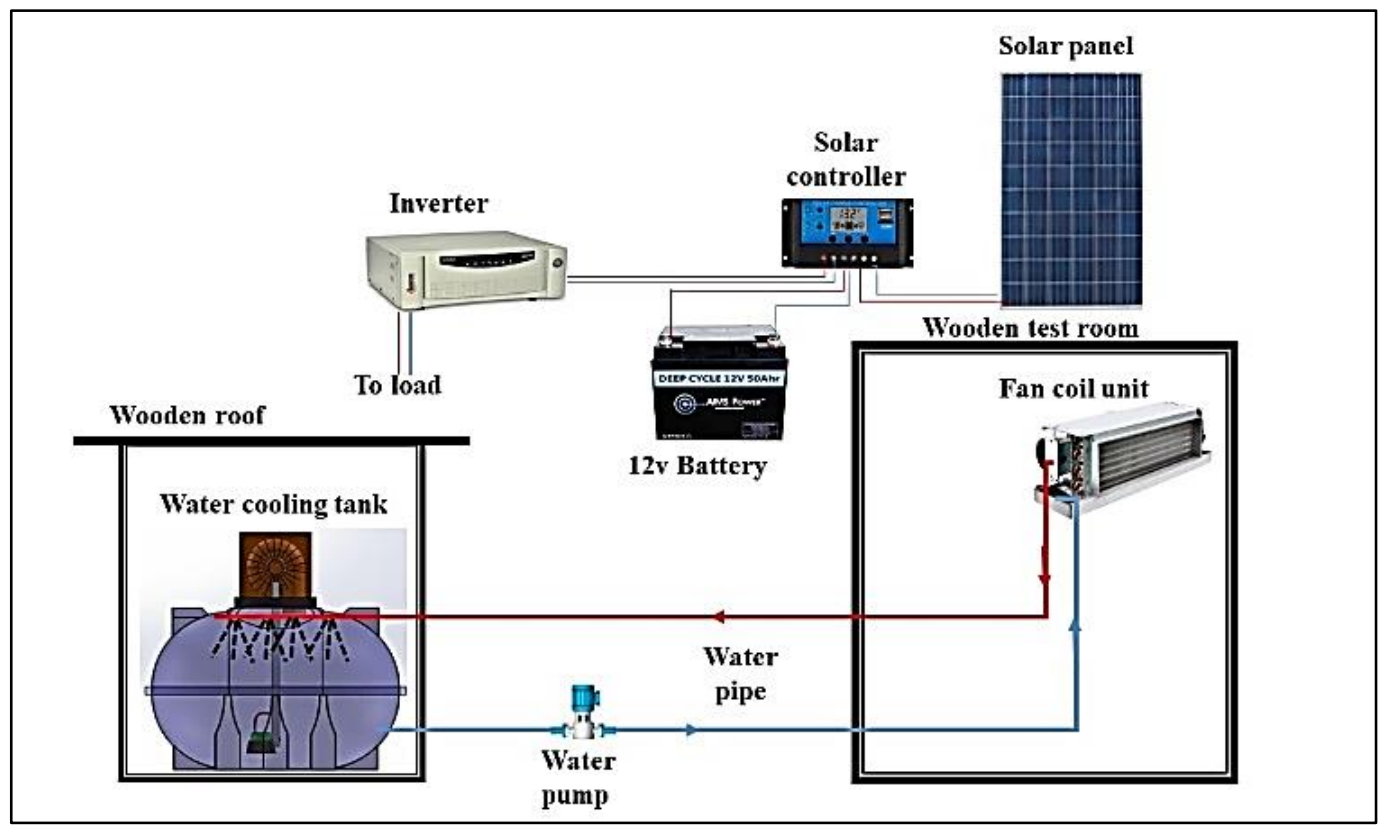

Figure 6. A schematic diagram of the system 


\section{BASIC EQUATIONS}

The equation adopted in calculating the heat losses from the water tank [11]:

$$
Q=m^{\circ}{ }_{w} c p\left(T_{\text {in }}-T_{\text {out }}\right)
$$

where, $Q$ heat transfer, $T_{\text {in }}$ and $T_{\text {out }}$ the inlet and outlet water tank temperature respectively, $c p$ specific heat of water.

Also the equation adopted in calculating the heat losses from the air at heat exchanger:

$$
Q=m_{\text {air }}^{\circ} c p\left(T_{\text {out }}-T_{\text {in }}\right)
$$

where, $T_{\text {in }}$ and $T_{\text {out }}$ the inlet and outlet air temperature respectively, $c p$ specific heat of air.

The Ratio of liquid to gas for water tank refrigeration: is the rate of flow of liquid to the rate of gas flow. Thermodynamically indicates that the heat removed from the water must be equal to the heat absorbs by the surrounding air $[12,13]$.

$$
\begin{gathered}
m^{\circ}{ }_{w} C p_{w}\left(T_{1}-T_{2}\right)=m_{a}^{\circ}\left(h_{2}-h_{1}\right) \\
\frac{m^{\circ}{ }_{w}}{m_{a}^{\circ}}=\frac{\left(h_{2}-h_{1}\right)}{C p_{w}\left(T_{1}-T_{2}\right)}
\end{gathered}
$$

$m^{\circ}{ }_{w} / m^{\circ}{ }_{a}=$ liquid to gas mass flow ratio $(\mathrm{kg} / \mathrm{kg})$.

$C p_{w}=$ specific heat of water $\left(\mathrm{kJ} / \mathrm{kg} .{ }^{\circ} \mathrm{C}\right)$.

$T_{l}=$ hot water temperature $\left({ }^{\circ} \mathrm{C}\right)$.

$T_{2}=$ cold water temperature $\left({ }^{\circ} \mathrm{C}\right)$.

$h_{2}=$ enthalpy of air-water vapor mixture at exhaust wet-bulb temperature $(\mathrm{kJ} / \mathrm{kg})$.

$h_{l}=$ enthalpy of air-water vapor mixture at inlet wet-bulb temperature $(\mathrm{kJ} / \mathrm{kg})$.

The amount of water drawn by the air in the form of vapor $[13,14]$ :

$$
m^{\circ}{ }_{w}=m_{a}^{\circ}\left(w_{2}-w_{1}\right)
$$

where, $\mathrm{w}_{2}$ and $\mathrm{w}_{1}=$ humidity ratio for inlet and outlet air respectively.

Humidity ratio in the air increased when the air is exposed to water due to increased evaporation [15].

\section{RESULTS AND DISCUSSIONS}

Tests were conducted in the hot season (July, August and September / 2018). Initially, the tank water temperature without the cooling device recorded for comparison, with the tank water temperature using the device. The test was conducted on 27 and 28/7 for the tank without any addition, without and with load (water supply to the house) respectively. On $31 / 7$ and $1 / 8$ the test was done with the wooden box placed without and with the load respectively. The test was then carried out on 4 and 6/8 with the box and under the shadow without and with the load respectively. The above tests showed that the temperature of the tank decreases with the load, because the water supplied to the tank from the water network public utility is less than the temperature of the water in the tank by $(35-32){ }^{\circ} \mathrm{C}$ as shown in Figure 7, for all the tests will be performed with load. It was also noted that the best reduction in temperature obtained by using a wooden box and shade compared to the temperature of the ambient but did not reach the appropriate temperature.

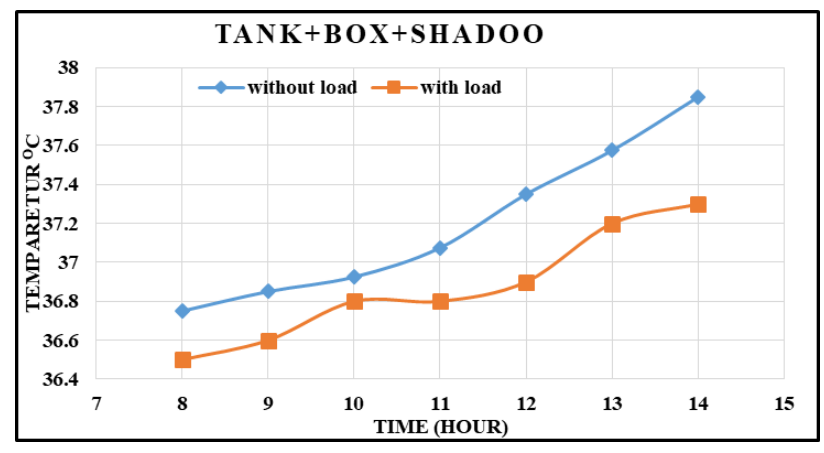

Figure 7. Comparison of water temperature of the tank without and with load

On 10/8 a test conducted, the air discharged only, and no insulation added to the tank where the water temperature maintained at (35-37) ${ }^{\circ} \mathrm{C}$ despite the ambient temperature rising to $(45){ }^{\circ} \mathrm{C}$. Because the heat absorbed from the ambient by the water was eliminated by forced evaporation by air discharge from the fan, as shown in Figure 8.

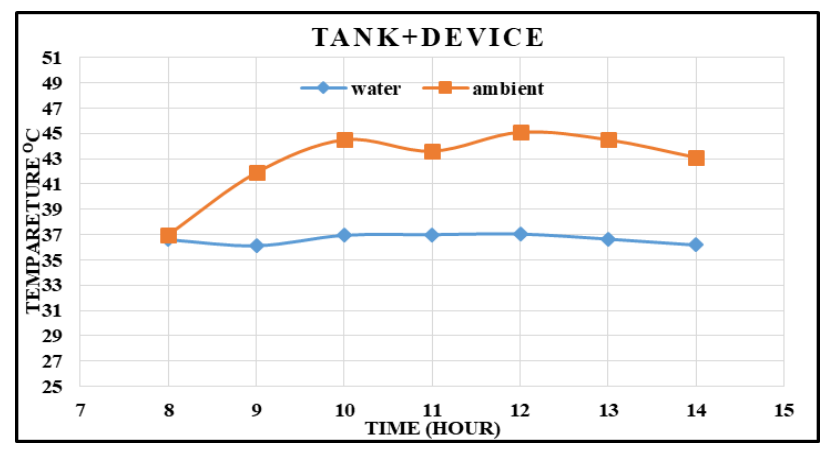

Figure 8. Comparison of the water temperature of the tank with the ambient

On $11 / 8$ the water pump was operated with the air fan, where the effect of the water diffusion is evident on the water temperature of the tank compared to the temperature of the surrounding which was the highest temperature at $3: 00 \mathrm{pm}$, reaching $44.6^{\circ} \mathrm{C}$, while the water temperature was $30.725^{\circ} \mathrm{C}$. Based on this, the device operation period extended to $4: 00 \mathrm{pm}$, to show the continued decline in water temperature until it reached $29.4^{\circ} \mathrm{C}$ therefore, the water temperature can be reduced proportionally to device operation period, as shown in Figure 9.

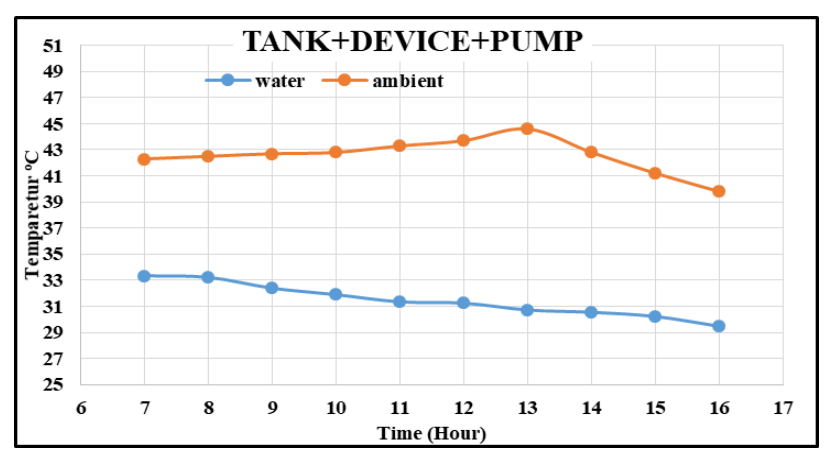

Figure 9. Decreasing the tank's water temperature compared with ambient 
On 18/8 the insulation box was used with air discharge and water pump, a noticeable drop in temperature compared to the previous reading because the box contributed to reducing ambient temperature impact. The test hours extended to 8:00 pm to get $27.5^{\circ} \mathrm{C}$, as shown in Figure 10 .

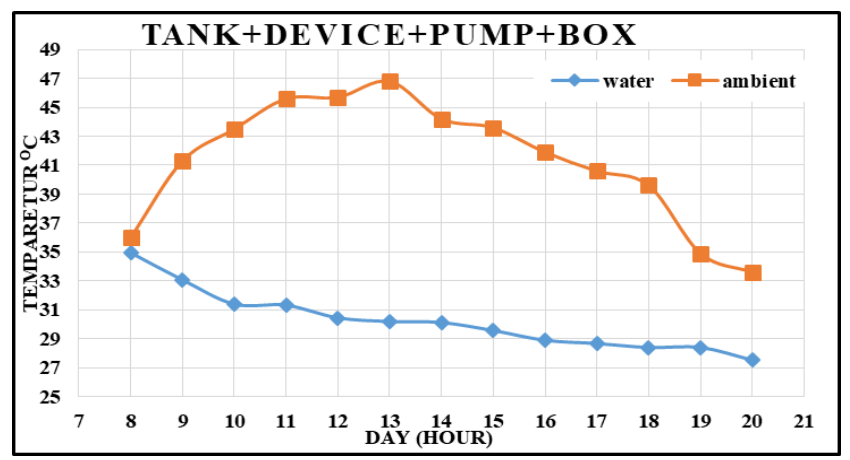

Figure 10. Decreasing water temperature compared to the ambient

Then on $24 / 8$, the roof was placed to provide shade above the reservoir with the insulating box. At 8:00 am the test started. The temperature decrease gradient was very close to the previous test, where the drop is only one degree at most times. However, the difference is significant between water and ambient temperatures as shown in Figure 11. The result was outstanding compared to the water of the uncool reservoir, Figure 12. After 8:00 pm the work of the device is continued non-stopped with the load until 8:00 am, the lowest temperature recorded $23.75^{\circ} \mathrm{C}$ compared to the temperature of water in the uncooled tank of $37.5^{\circ} \mathrm{C}$ at the same time.

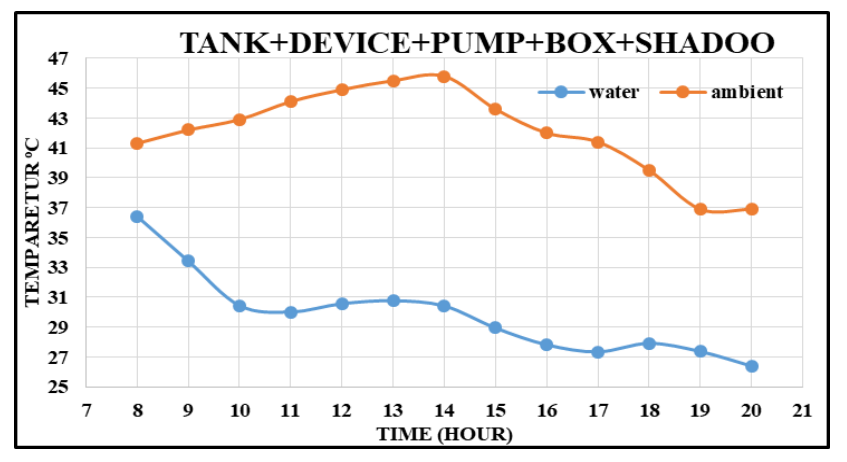

Figure 11. Decreasing the tank's water temperature compared to the ambient

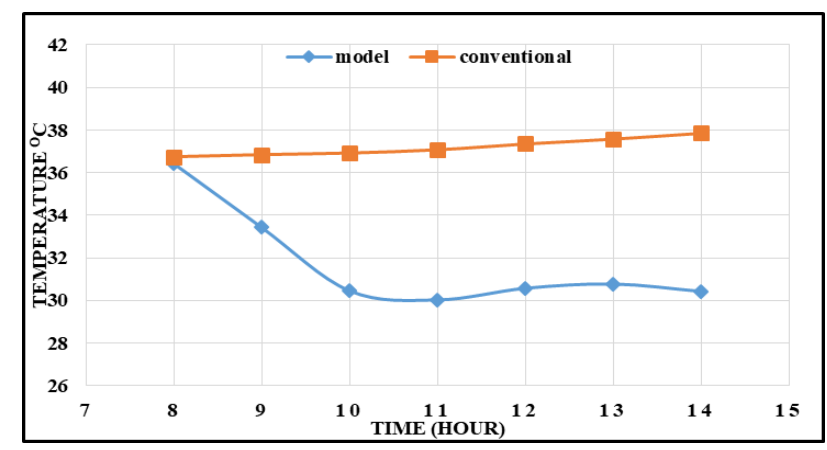

Figure 12. Uncooled tank's water temperature compared with the cooled tank

Preservation of this degree $\left(23.75^{\circ} \mathrm{C}\right)$ has been maintained by continuously working of the device and remained almost constant to the hot afternoon compared to the temperature of the uncooled tank, which reached the temperature at the 2:00 pm of about $43^{\circ} \mathrm{C}$ with a difference of $46.5 \%$.

A test carried out to examine the effect of improving the surrounding temperature of the tank; water jets used to reduce the ambient temperature on 10/9. The water pump running on DC (24 volts) is used to discharge the water through a $5 \mathrm{~m}$ rubber tube, where it was rotated around the tank roof and installed on the tube ten water jets. When comparing the readings with the test without water jets, it observed that an approximation behavior is noticed of the water temperature in the tank as shown in Figure 13.

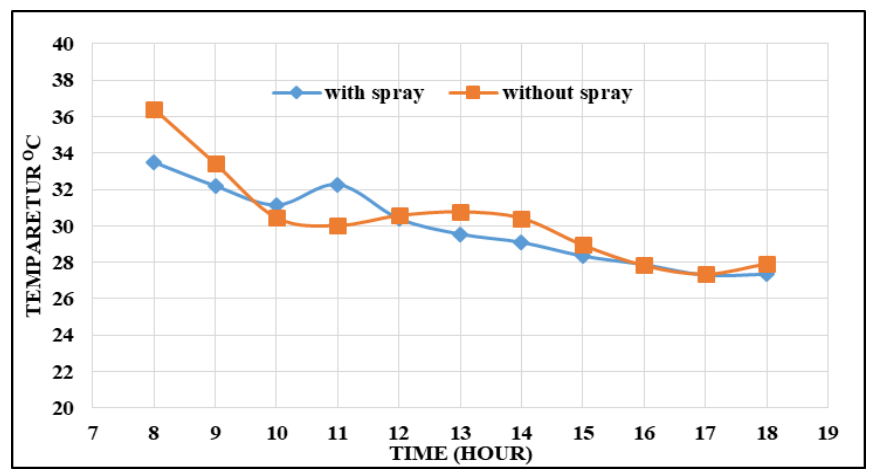

Figure 13. Tank's water temperature cooled by jets vs. without jets

The low water temperature was used for the purpose of cooling the air and the water tank was connected to the air conditioner located in the mini test room and the first test was on 25/8/2019 at one o'clock in the afternoon. The results showed a clear and significant decrease in room temperature, where it was $47.2^{\circ} \mathrm{C}$ when starting and became $34.5^{\circ} \mathrm{C}$ after only 20 minutes had passed. The decrease continued and a degree was maintained until it reached $33.5^{\circ} \mathrm{C}$ compared to the outside air temperature of $51.6^{\circ} \mathrm{C}$. The start of a slight rise in the temperature of the reservoir water from $27^{\circ} \mathrm{C}$ when the test began to $31^{\circ} \mathrm{C}$ in the fourth afternoon as a result of the thermal gain from the cooled air and the surrounding area as shown in Figure 14.

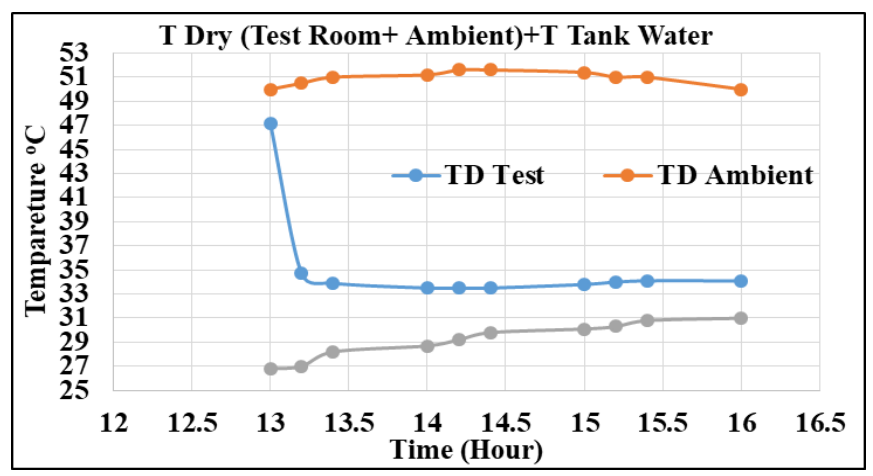

Figure 14. Dry room air temperature compared to ambient air temperature and coolant tank water

The temperature of the house room (dry and wet), that was cooled by the regular evaporative cooler, was measured and compared with the test room temperature, showed a large convergence with the dry temperature where the cooler provided a lower temperature with approximately one 
temperature, Figure 15.

As for the wet bulb temperature, the result was very good for the test room, as it was high at about seven degrees due to the addition of moisture by evaporative cooling, Figure 16. This decrease led to a clear difference in the relative humidity (94-90) \% for the home room, while (51-45) \% of the testing room provides more comfortable and acceptable space compared to the home room, Figure 17.

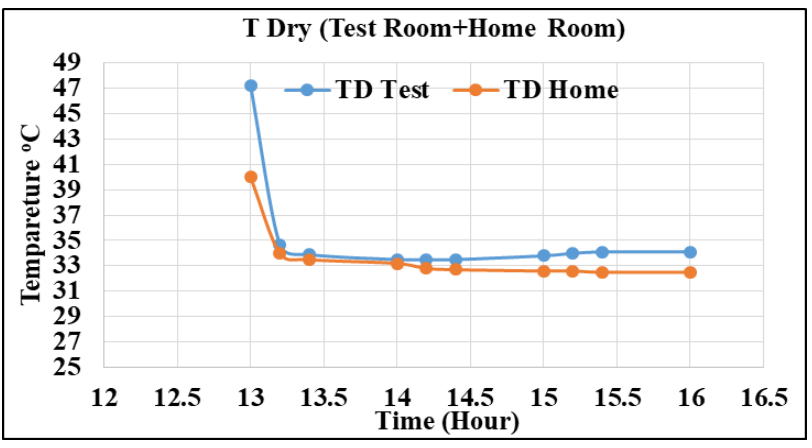

Figure 15. Dry test room air temperature compared to home room temperature

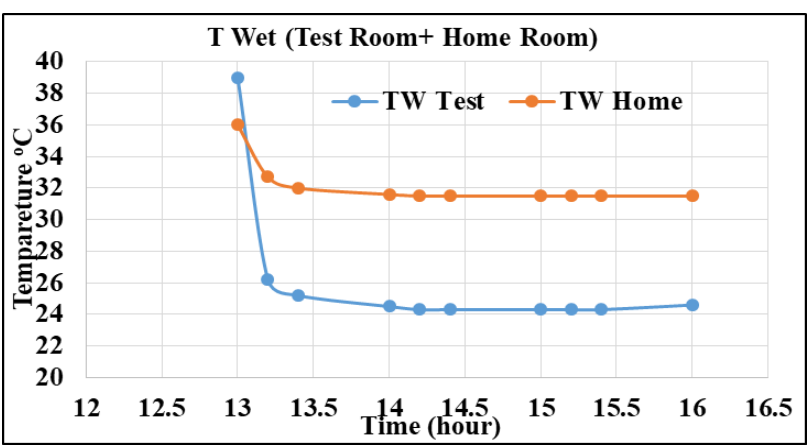

Figure 16. Wet bulb test room air temperature compared to house room temperature

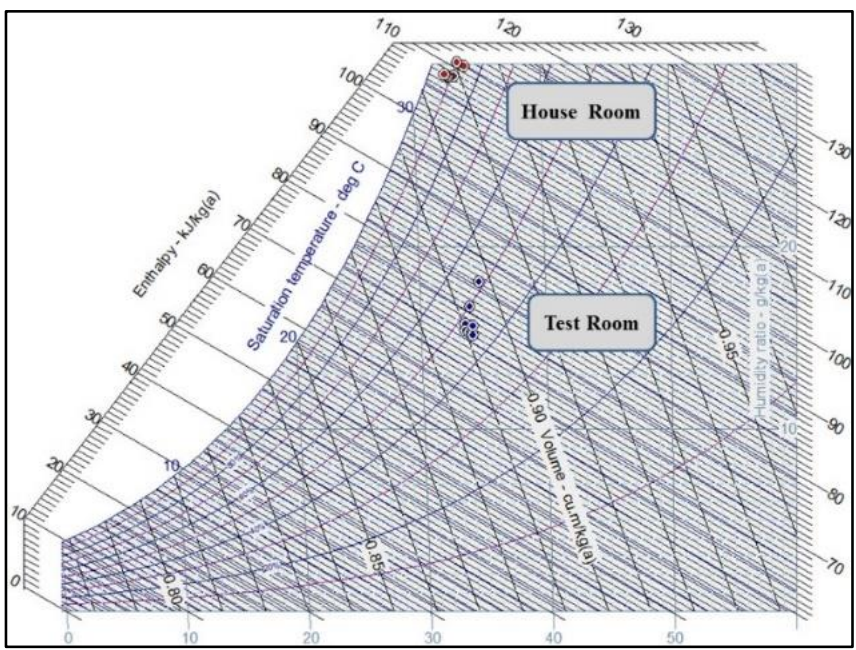

Figure 17. The condition of the test room air compared to the house room on the psychrometric chart

On 26/8/2019 the test was repeated to confirm the results, and it was very close to the previous test day. On the 27/8/2019, the test was repeated for a longer period of time, which amounted to eighteen hours, starting from twelve noon and until six o'clock in the morning from the next day to observe the possibility of maintaining the temperature of the test room and water tank. Where the temperature of the room air and water tank was almost identical to the previous two tests, where the room temperature was preserved up to $33^{\circ} \mathrm{C}$ after which it started to rise until it reached $34.4^{\circ} \mathrm{C}$ at four o'clock due to the thermal gain from the outside environment, that led to the high temperature of the water tank. After that, it started to decrease depending on the ambient temperature decrease and overcoming the thermal gain due to the continued cooling of the tank's water, to continue the gradual decrease until six o'clock in the morning, as the room temperature reached $29.8^{\circ} \mathrm{C}$, Figure 18 , the wet bulb air temperature was also very good compared by the ambient and the air in the house room, the difference was close to previous tests.

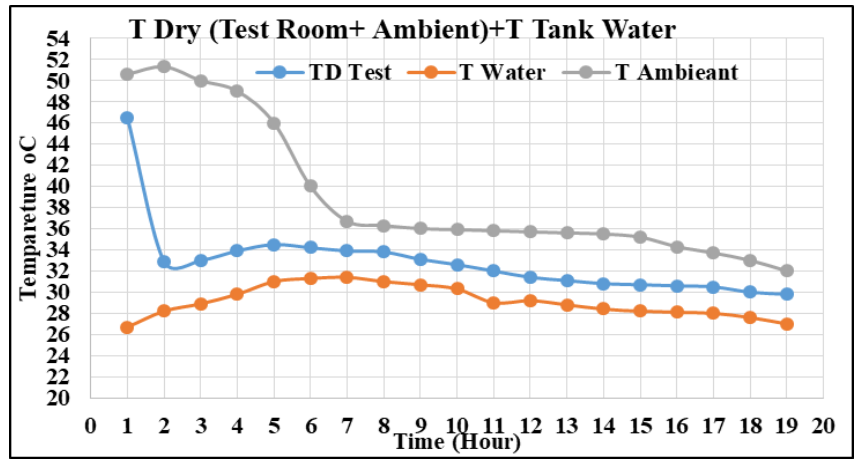

Figure 18. Room air temperature compared to the ambient and water tank temperature

The temperature of the water exit from heat exchanger is very close to the temperature of the test room, and this is an indication of the quality of the heat exchanger, Figure 19. The room temperature depends on the temperature of the water tank, which can be reduced by increasing the air flow which leads to increased evaporation as well as an increase the volume of the water tank to provide enough water to overcome the thermal gain.

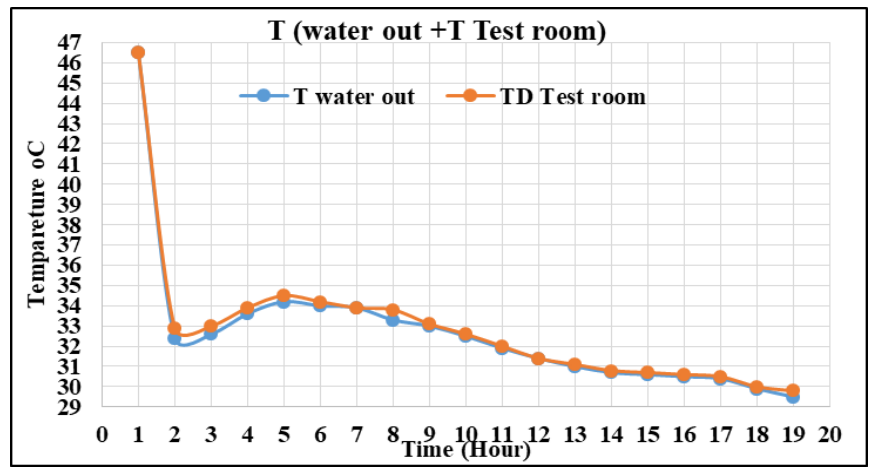

Figure 19. Room air temperature compared to the temperature of the water leaving the exchanger

\section{POWER CONSUMPTION}

The power consumption of the system is very low comparative with traditional air evaporative cooler, whereas, the power consumed by the system is 150 watt, while the evaporative cooler is 440 watt and the test room condition is better than the home room by decrease the relative humidity. The power remains almost constant with the test time. 


\section{CONCLUSIONS}

It The study presented is to rooms air conditioning by cooling the conventional water tank using hot summer air and solar energy, using the evaporation property that extraction the potential heat of the evaporation from the water thereby reducing the water temperature, the operation was done using a fan to propel the air inside the tank and water pump to circulate water and increase air contact area with water. Experiments were conducted in external environments and on separated days, the experiments have proven the success of this method in reducing the tank water temperature compared with the ambient temperature and the uncooled tank, as well as reducing the room air temperature by approximately the temperature of the air cooled by the evaporative air cooler and with a wet temperature and low relative humidity, as follow:

1 - The rate of the temperature of the tank's water dropped to $23^{\circ} \mathrm{C}$, which can be maintained by the device continuously working while the water temperature in the conventional tank is more $43^{\circ} \mathrm{C}$ at $46^{\circ} \mathrm{C}$ ambient temperature, which is expected increase through the day time.

2- The dry air temperature of the test room is very close to the temperature of the house room air, which ranges between (30-33) ${ }^{\circ} \mathrm{C}$, compared to the ambient temperature that ranges between $(45-50){ }^{\circ} \mathrm{C}$.

3 - The wet air temperature of the test chamber is lower than the room air temperature, by six to seven degrees Celsius.

4- Decrease wet air temperature for the test room led to a noticeable decrease in the relative humidity from (94-90) \% for the house room to (51-45) \% for the test room, which led to providing a more comfortable and acceptable space than the house room air.

5- The power consumption of the system is lower than traditional air evaporative cooler in a rate of $67 \%$.

6- Used this device instead of the evaporative air cooler leads to the disposal of odors, dust and toxic materials resulting from waste, vehicle exhaust or fire, as the air cooler pulls the outside air and enters it into the space, while in the test room the internal air is circulated so that the air is pure and unpolluted.

7- The cost of the devices is very low, and it is affordable to all, and the consumption of electricity is very low, and it can run on a simple solar PV panel. Therefore, it is useful to use these devices in hot places to provide low-temperature water and acceptable for domestic use and room air condition.

8- The wooden box is made on the size of the tank as a thermal insulation at a low cost to suit the testing system and private home use. In the case of large buildings, the required insulators can be used, depending on the building and the ambiance surrounding, in addition to shade roofing.

9- To develop innovation and increase its efficiency, a large tank can be used as well as increasing the surface area of evaporation by spraying water on porous material sheets that are installed under the water stream with an increase in the amount of air flowrate for evaporation as well as increasing the flowrate of water to the heat exchanger and uses the water exchanger (fan and coil unit).

10- This technology can be applied in the air conditioning of low-cost buildings, green house, big factories and companies that require very large air condition system or open buildings, because it has a good properties, especially the ease of construction, low cost and energy consumption is very low, and the ease of increasing and reducing the size of the system according the need.

\section{REFERENCES}

[1] https://www.globalsecurity.org/military/world/iraq/clim ate.htm, accessed on Jan. 17, 2020.

[2] Duffie, J.A., Beckman, W.A. (2013). Solar Engineering of Thermal Processes. Fourth Edition, Wiley.

[3] Zahedi, H.R., Adam, N.M., Sapuan, S.M., Ahmad, M.M. (2007). Effect of storage tank geometry on performance of solar water tank heater. Journal of Scientific and Industrial Research, 66: 146-151.

[4] Cengel, Y.A. (2002). Heat Transfer: A Practical Approach. Second Edition, Mcgraw-Hill (Tx).

[5] Bedre, P.B., Tiwari, H.U. (2015). Design and development of combined direct and indirect evaporative cooling system. International Engineering Research Journal (IERJ) Special Issue, 2: 4611-4615.

[6] Amer, O., Boukhanouf, R., Ibrahim, H.G. (2015). A review of evaporative cooling technologies. International Journal of Environmental Science and Development, 6(2): 111. https://doi.org/10.7763/IJESD.2015.V6.571

[7] Aherne, V.J., Mgt, M. (2009). Water Conservation in Cooling Towers. The Australian Institute of Refrigeration, Air Conditioning and Heating. ISBN 9780-949436-47-4.

[8] Keister, T. (2008). Cooling Water Management Basic Principles and Technology. Pennsylvania, ProChemTech International, Inc.

[9] Misra, D., Ghosh, S. (2018). Evaporative cooling technologies for greenhouses: A comprehensive review. Agricultural Engineering International: CIGR Journal, 20(1): 1-15.

[10] Vairagade, S.G., Shrivastava, P., Wandhile, P., Kale, S. (2017). A review paper on evaporative cooling methods. IJARIIE-ISSN, 3(2): 2395-4396.

[11] Arora, R.C. (2009). Refrigeration and air conditioning. Tata McGraw Hill Company, 3rd edition, ISBN: 0-07463010-5.

[12] Hall, B.M., Bergman, A.M. (2016). Faculty of Engineering and Applied Science.

[13] Stoecker, W.F., Stoecker, W.F. (1998). Industrial Refrigeration Handbook. New York: McGraw-Hill, Vol. 10 .

[14] Heidarinejad, G., Pasdarshahri, H. (2011). Potential of a desiccant-evaporative cooling system performance in a multi-climate country. International Journal of Refrigeration, 34(5): 1251-1261. https://doi.org/10.1016/j.ijrefrig.2011.03.008

[15] Poku, R., Oyinki, T.W., Ogbonnaya, E.A. (2017). The effects of evaporative cooling in tropical climate. American Journal of Mechanical Engineering, 5(4): 145150. https://doi.org/10.1016/10.12691/ajme-5-4-5 